Research Article

\title{
Evaluation of prescribing pattern and adverse effects of fixed dose combination of non-steroidal anti-inflammatory drugs
}

\author{
Alpa Pragnesh Gor ${ }^{1 *}$, B. K. Shah ${ }^{2}$
}

\author{
${ }^{1}$ Department of Pharmacology, \\ Pramukh Swami Medical \\ College, Karamsad, Gujarat, \\ India \\ ${ }^{2}$ Department of Pharmacology, \\ College of dental science and \\ research centre, Ahmadabad, \\ India
}

Received: 07 May 2016

Accepted: 16 May 2016

\section{*Correspondence to:}

Dr. Alpa Pragnesh Gor,

Email: alpapg

@ charutarhealth.org

Copyright: (C) the author(s), publisher and licensee Medip Academy. This is an openaccess article distributed under the terms of the Creative Commons Attribution NonCommercial License, which permits unrestricted noncommercial use, distribution, and reproduction in any medium, provided the original work is properly cited.

\begin{abstract}
Background: The use of fixed does combination of drugs is a major controversial health related issue. The non-steroidal anti-inflammatory drugs (NSAIDs) is one of the most frequently use drugs in population. The present study was undertaken to observe the pattern of use fixed dose combinations of NSAIDs and its adverse effects.

Methods: The study was approved by the institutional ethics committee. Randomly selected patients irrespective of age and sex, who were on NSAIDs from the indoor and outdoor patients of paediatric, medicine and orthopaedic departments, were included in the study. Patients with history of administration of NSAIDs in last 30 days kidney, liver, acid-peptic disease, pregnancy and lactation were excluded from the study. WHO causality assessment scale was used for adverse reactions occurred due to fixed dose combinations (FDCs) of NSAIDs. The preventability, severity of the adverse drug reactions (ADRs) was evaluated.

Results: Total one thousand participants were included in the study, among them 112 had received analgesic FDCs. Diclofenac+paracetamol and ibuprofen+paracetamol were the highest used in the study. Maximum combinations were found in the age group 41-60 years, the second highest (37 combinations) were in age group of 19-40 years. Fourty-two ADRs were due to the use of FDCs of NSAIDS. It was found that nimesulide+paracetamol was culprit in causing ADRs in 60 percent and diclofenec+paracetamol was in 40 percent of the participants. GI related adverse reaction observed in 28 participants. It was found that eighty percent of the adverse reaction was possible in nature. Most of the ADRs were mild in nature. It was evident that majority of ADRs were definitely preventable.
\end{abstract}

Conclusions: There is a wide use of analgesic FDCs which should be discouraged.

Keywords: FDCs, NSAIDs, ADR

\section{INTRODUCTION}

In today's medical practice, the rationality of fixed dose combinations (FDCs) is one of the common controversial and debated issue. Many FDCs are lacking in pharmacodynamic or pharmacokinetic advantages. Due to irrationality of FDCs, chances of occurring of unnecessary risk of adverse drug reactions are increasing. When two or more drugs are available in same formulation then it should meet the following criteria i.e the dosage of each ingredient meets the requirement of a defined population group and when the combination has a proven advantage over single compounds administered separately in therapeutic effect, safety or compliance. ${ }^{1}$ The $19^{\text {th }}$ WHO model list of essential medicines contains only 25 approved FDCs whereas the national list of essential drugs of India enlists 14 FDCs., ${ }^{2,3}$ These authorities have approved only handful of FDCs but market is flooded with hundreds of irrational FDCs.

Use of FDCs is constantly expanding to search for more efficacious and better tolerated compounds. Selfmedication or over the counter (OTC) use of medicines has also increase worldwide. When patient need one 
medicine he/she may receive two or more medicine in combination form which can cause unnecessary risk. Large proportions of the drugs that are available in the market are of little importance in terms of providing primary healthcare. Irrational drug use can lead to reduction in quality of drug therapy, increased risk of side effects, drug resistance etc. ${ }^{4}$

The non-steroidal anti-inflammatory drugs (NSAIDs) are one of the most frequently used drugs for its antiinflammatory, analgesic and antipyretic activities. There is no synergism when two drugs are combined in single formulation when they acting on the same enzyme. In India, a variety of NSAID combinations are available, often as over the counter products. For NSAID FDCs, 124 formulations were marketed, of which 34 (27\%) were centrally approved and $90(73 \%)$ were unapproved. ${ }^{5}$ Combining two NSAIDs does not and cannot improve the efficacy of treatment. It only adds to the cost of therapy and more importantly, to the adverse effects. ${ }^{1}$ The use of fixed-dose combinations may reduce flexibility in dose titration, or conversely may expose patients to unnecessarily large doses of NSAIDs with consequent adverse effects, particularly in susceptible patients. Furthermore, combinations will not be suitable for patients with contraindications to either drug alone. For example, paracetamol should be used with caution in patients with pre-existing liver disease and other traditional NSAIDs in patients with history of gastrointestinal ulcers or renal impairment. Looking to the scenario the present study was undertaken to observe the pattern of use fixed dose combinations of NSAIDs and its adverse effects.

\section{METHODS}

The descriptive, study was conducted at Shri Krishna Hospital, a tertiary care teaching hospital in central Gujarat, India. The study was approved by the institutional ethics committee. Randomly selected patients irrespective of age and sex, who were on nonsteroidal anti-inflammatory drugs (NSAIDs) from the indoor and outdoor patients of paediatric, medicine and orthopedic departments, were included in the study. Patients with history of administration of NSAIDs in last 30 days, kidney, liver, acid-peptic disease, pregnancy and lactation were excluded from the study. Written informed consent of the participants as well as parents (in case of paediatric patients) was taken before their enrolment in the study. All participants were followed for one month, either during the visit to the hospital or by the telephonically. Data were analysed for demographic information, use of FDCs and its adverse effects. WHO causality assessment scale was used for adverse reactions occurred due to FDCs of NSAIDs. ${ }^{6}$ The preventability of the ADRs was evaluated by using the criteria of Schumock et al modified by Lau et al. ${ }^{7}$ The severity of ADRs was categorized into mild, moderate and severe using ADR severity assessment scale of Hartwig et al. ${ }^{8}$

\section{RESULTS}

Total one thousand participants were included in the study, among them 112 had received analgesic FDCs. Sixty (53.57\%) participants were females and 52 $(46.43 \%)$ were male. Total seven combinations of analgesic FDCs were frequently prescribed among all participants. Diclofenac+paracetamol and ibuprofen+paracetamol were the highest used in the study. Second highest combinations were nimesulide+paracetamol and acelofenac+paracetamol. Other combinations i.e Diclofenac + paracetamol + serratiopeptidase, paracetamol + cetirizine + phenylpropalamine, diclofenac+dicyclomine were also observed in the study in few patients. Maximum combinations were found in the age group 41-60 years, the second highest (37 combinations) were in age group of 19-40 years. Seventeen elderly participants received combinations of NSAIDs (Table 1).

Table 1: Age wise distribution of combinations of NSAIDs.

\begin{tabular}{|llllll|}
\hline Combinations & $\mathbf{1 - 1 8}$ years & $\mathbf{1 9 - 4 0}$ years & $\mathbf{4 1 - 6 0}$ years & $\mathbf{7 6 0}$ years & Total $(\%)$ \\
\hline Diclofenac + paracetamol & 4 & 16 & 19 & 10 & 49(43.75) \\
\hline Ibuprofen+paracetamol & 4 & 13 & 20 & 5 & $42(37.5)$ \\
\hline Nimesulide + paracetamol & 1 & 4 & 5 & 0 & $10(8.93)$ \\
\hline Acelofenac + paracetamol & 0 & 2 & 3 & 2 & $7(6.25)$ \\
\hline Diclofenac + paracetamol +serratiopeptidase & 1 & 0 & 1 & 0 & $2(1.78)$ \\
\hline Paracetamol+ ceterizine + phenylpropalamine & 0 & 1 & 0 & 0 & $1(0.89)$ \\
\hline Diclofenac+dicyclomine & 0 & 1 & 0 & 0 & $1(0.89)$ \\
\hline
\end{tabular}

Total 192 adverse drug reactions (ADRs) were observed among all participants who received NSAIDs irrespective of combinations (Table 2). Fourty two ADRs were due to the use of FDCs of NSAIDS. It was found that nimesulide+paracetamol was culprit in causing ADRs in 60 percent and diclofenec+paracetamol was in 40 percent of the participants. GI related adverse reaction observed in 28 participants. Headache, increased BP, edema, increase 
liver function test (LFT), urticarial, palpitation, increase creatinine were other observed ADRs (Table 3).

Table 2: System wise distribution of ADRs.

\begin{tabular}{|lll|}
\hline Affected System & Patients & Percent \\
\hline Cardiovascular system & $\mathbf{4 8}$ & \\
\hline Increased B.P. & 34 & 17.7 \\
\hline Palpitation & 14 & 7.3 \\
\hline Gastrointentestinal system & $\mathbf{5 6}$ & \\
\hline Gastritis & 29 & 15.1 \\
\hline Diarrhoea & 4 & 2.1 \\
\hline Vomiting & 7 & 3.6 \\
\hline Constipation & 1 & .5 \\
\hline Nausea & 6 & 3.1 \\
\hline Decreased appetite & 9 & 4.7 \\
\hline Respiratory system & $\mathbf{1}$ & \\
\hline Breathlessness & 1 & .5 \\
\hline Central nervous system & $\mathbf{3 2}$ & \\
\hline Headache & 15 & 7.8 \\
\hline Confusion & 3 & 1.6 \\
\hline Giddiness & 12 & 6.3 \\
\hline Paresthesia & 2 & 1.0 \\
\hline Eye & $\mathbf{9}$ & \\
\hline Blurred vision & 9 & 4.7 \\
\hline Electrolyte imbalance & $\mathbf{7}$ \\
\hline Edema & 7 & 3.6 \\
\hline Heamatology & $\mathbf{1 0}$ \\
\hline Anemia & 6 \\
\hline Decreased T.C. & 3.1 \\
\hline Liver & 4 \\
\hline Hepatotoxicity & $\mathbf{1 1}$ \\
\hline Kidney & 11 \\
\hline Increased creatinine & $\mathbf{1 2}$ \\
\hline Decrease urination & 2 \\
\hline Skin & 10 \\
\hline Urticaria & $\mathbf{6}$ \\
\hline Total & 6 \\
\hline & $\mathbf{1 9 2}$ \\
\hline & \\
\hline
\end{tabular}

It was found that eighty percent of the adverse reaction was possible in nature, remaining were probable and unlikely in nature (i e. $18 \%$ and $2 \%$ respectively).

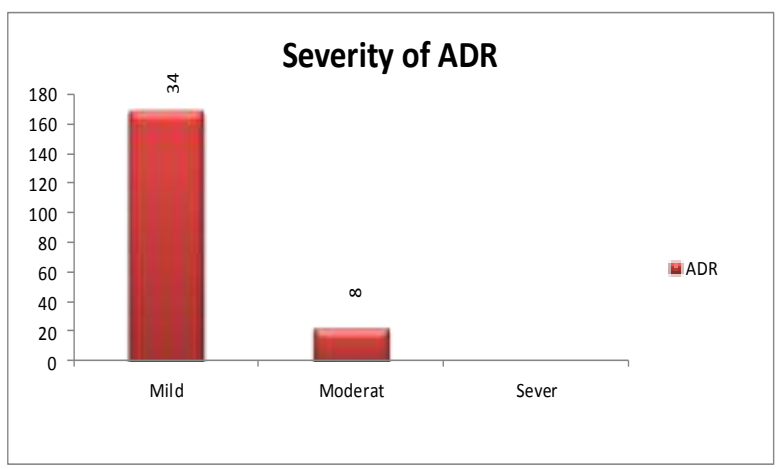

Figure 1: Classification of adverse effects on the basis of severity.

Most of the ADRs were mild in nature. Severe type of ADR was not found in any patient (Figure 1). It was evident that majority of ADRs were definitely preventable (Figure 2).

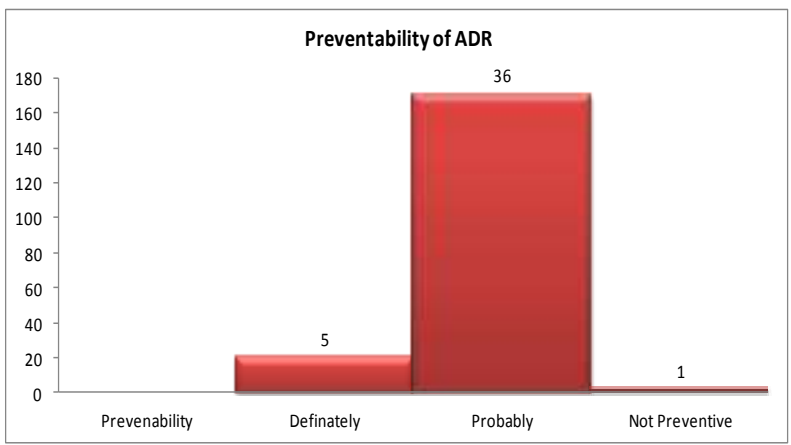

Figure 2: Classification of adverse effects on the basis of preventability.

Table 3: Analysis of adverse effects caused by analgesic FDCs.

\begin{tabular}{|lll|l|}
\hline Combinations & Prescribed & No. of ADR(\%) & Nature of ADR \\
\hline Ibuprofen+paracetamol & 42 & $13(30.95 \%)$ & $\begin{array}{l}\text { GI intolerance (9), edema (1), urticaria } \\
(1), \text { breathlessness (1), giddiness (1) }\end{array}$ \\
\hline Diclofenac+paracetamol & 49 & $20(40.81 \%)$ & $\begin{array}{l}\text { GI intolerance (16), palpitation (2), } \\
\text { oliguria (1), increase creatinine (1) }\end{array}$ \\
\hline Nimesulide+paracetamol & 10 & $6(60 \%)$ & $\begin{array}{l}\text { Increased LFT (2), vomiting (2), edeme } \\
(1), \text { blurring of vision (1) }\end{array}$ \\
\hline Diclofenac+dicyclomine & 1 & $1(100 \%)$ & Headache \\
\hline Paracetamol+cetrizine+phenylpropalamine & 1 & $1(100 \%)$ & Increased blood pressure \\
\hline Aceclofenac+paracetamol & 7 & $1(14.28 \%)$ & Constipation \\
\hline Diclofenac+paracetamol+serratiopeptidase & 2 & $0(0)$ & \\
\hline Total & 112 & $42(37.5 \%)$ & \\
\hline
\end{tabular}




\section{DISCUSSION}

World Health Organization (WHO) has suggested a pain management protocol which states that simple analgesics should be selected first and in case the patient does not respond to that, one can choose any other non-steroidal anti-inflammatory drug (NSAID) and thereafter give a combination of NSAID with opioid analgesic. There is no place for fixed dose combination (FDC) of two NSAIDs in it. Two drugs having the same mechanism of action are ideally not combined in a FDC, as they serve no added advantage and their adverse drugs reactions are additive, which may increase the potential of developing serious consequences. ${ }^{9}$

Paracetamol, ibuprofen and diclofenac sodium are some of the most frequently used NSAIDs in clinical practice. In India, a number of fixed dose drug combinations of NSAIDs are available, and are used often as over the counter (OTC) products. Fixed dose combination (FDC) of NSAIDs like paracetamol with diclofenac and with ibuprofen are widely prescribed for treating fever, pain or inflammation. These combinations are being extensively marketed by pharmaceutical industry claiming higher efficacy compared to either of the drug used alone. However, there is inadequate documented evidence comparing the efficacy of these FDCs over the individual components.

In the present study out of one thousand prescriptions eleven percent prescription were containing FDCs of different NSAIDs. Study by Kastury $\mathrm{N}$ et al, stated that analgesic combinations are the second most prescribing drug category of FDCs in Indian scenario. ${ }^{10}$ He reported fifteen percent of FDCs of analgesic combinations use in his study. In present study most frequently prescribing FDCs were diclofenac+paracetamol and ibuprofen+paracetamol. Other two combinations were nimesulide+paracetamol and aceclofenac+paracetamol were ranked third and fourth in this study. Studies have proven that there is no single advantage of combining these drugs. Its efficacy has not been proven. ${ }^{1}$

Nimesulide containing FDC were prescribed to ten patients in the study. Out of them, one belonged to pediatric age group. Nimesulide, a preferential cyclooxygenase (COX-2) inhibitor was first launched in Italy in 1985 and subsequently marketed in more than 50 countries including India. In 2003, following worldwide reports of fatal adverse events in children, some countries banned it while others have issued restrictions in pediatric usage. Published studies from India indicate rampant abuse of nimesulide. At least 12 paediatric preparations of nimesulide are available in India, which affirms the widespread use of the drug in children. ${ }^{12}$

In the present study, two prescriptions were issued containing FDC of serratiopeptidase. The clinical evidence offered in claims of anti-inflammatory action of serratiopeptidase is not substantial and various studies have raised doubts about their efficacy. ${ }^{11}$ It does not offer any particular advantage over the individual drugs despite the claim that serratopeptidase promotes more rapid resolution of inflammation and on the other hand, the patient is exposed to greater risk of gastrointestinal (GI) irritation and serious bleeding from unsuspected peptic ulceration. ${ }^{13}$ There was one prescription containing phenylpropanolamine as a component of FDC has been found. Phenylpropanolamine is an ingredient used in many over-the-counter (OTC) and prescription cough and cold medications as a decongestant and in OTC weight loss products. Because of continued reports to the FDA of hemorrhagic stroke associated with phenylpropanolamine and the results of the Yale study, food and drug administration (FDA) on November 6,2000 ordered steps to remove phenylpropanolamine from all drug products and has requested that all drug companies discontinue marketing products containing phenylpropanolamine. On the same day FDA has issued a public health advisory concerning the risk of hemorrhagic stroke or bleeding into the brain, associated with phenylpropanolamine hydrochloride. $^{14,15}$ It was found, FDC containing diclofenec+dicyclomine in one case. These FDCs are not only irrational but also could be dangerous. The antipyretic drug promotes sweating and thereby helps in heat dissipation. On the other hand, the anticholinergic antispasmodic drug inhibits sweating. Combining these two can result in dangerous elevation of the body temperature. ${ }^{16,17}$ Some such fixed drug combinations are now banned in India but still they are available in India. ${ }^{18}$

In the study, 12 patients reported ADRs related to kidney. Analgesic cause peculiar type of nephropathy that is called as analgesic nephropathy which increases when analgesic combination is taken. Analgesic nephropathy manifests papillary necrosis and nephritis occurs. ${ }^{19}$

Funding: No funding sources

Conflict of interest: None declared

Ethical approval: The study was approved by the Institutional Ethics Committee

\section{REFERENCES}

1. Chandler S, Gautam, Saha L. Fixed dose drug combinations (FDCs): rational or irrational: a view point. British Journal of Clinical Pharmacology. 2008;65:795-6.

2. 19th WHO Model List of Essential Medicines (April 2015). Available at http:// www.who.int/ medicines/ publications/ essential medicines/ eml2015_8-may15.pdf. Accessed on 10 October2015.

3. Department of pharmaceuticals. Available at http:// pharmaceuticals.gov.in/ pdf/ nlem.pdf. Accessed on 10 October 2015.

4. Raut S, Dhone P, Pise N, Verma R, Gupta RK. Current pattern of use of irrational fixed dose combinations: a prescription audit study. Research Journal of Pharmaceutical, Biological and Chemical Sciences. 2012;3(4):617-22. 
5. Mcgettigan P, Roderick P, Mahajan R, Kadam A, Pollock AM. Use of fixed dose combination (FDC) drugs in india: central regulatory approval and sales of FDCs containing non-steroidal anti- inflammatory drugs (NSAIDs), metformin, or psychotropic drugs. PLoS Med. 2015;12(5):e1001826.

6. The use of the WHO-UMC system for standardised case causality assessment. Available at http://whoumc.org/ graphics/ 24734. pdf. Accessed on 10 October 2015.

7. Schumock GT, Thornton JP. Focusing on the preventability of adverse drug reactions. Hosp Pharm. 1992;27:538.

8. 8.http://edusanjalpharmacology.blogspot.in/2012/12/ severity-assessment-of-adrs.html ( accessed on oct 10, 2015)

9. Tripathi SA, Shah R, Sharma DC. Analgesic activity of fixed dose combinations of paracetamol with diclofenac sodium and paracetamol with tramadol on different pain models in healthy volunteers a randomized double blind crossover study. J Anaesthesiol Clin Pharmacol. 2012;28:465-9.

10. Kastury N, Singh S, Ansari KU. An audit of prescription for rational use of fixed dose drug combinations. Indian J Pharmacol. 1999;31:367-9.

11. Chopra D, Rehan HS, Mehra P, Kakkar AK. A randomized, double-blind, placebo-controlled study comparing the efficacy and safety of paracetamol, serratiopeptidase, ibuprofen and betamethasone using the dental impaction pain model. Int $\mathbf{J}$ Oral Maxillofac Surg. 2009;38:350-5.

12. Gupta P, Sachdev HPS. Safety of oral use of nimesulide in children: systematic review of randomized controlled trials. Indian Pediatrics. 2003;40:518-31.

13. Shah SA, Nerukar RP. Evaluation of prescribing trends and rationality of use of oral proteolytic enzymes. Ind J Pharmacol. 2013;45:309-10.

14. Gor AP, Kharod NM .Nimesulide induced gastritis in a 10 year old child - a case report. Int J Curr Pharm Res. 2011;3(2):163-4.

15. Saha K. Use of nimesulide in Indian children must be stopped. British Med J. 2003;326(7391):713.

16. Legal Requirements for the sale and purchase of drug products containing pseudoephedrine, ephedrine, and phenylpropanolamine. Available at http:// www.fda.gov/ drugs/ drugsafety/ informationbydrugclass/ ucm150767.htm. Accessed on 10 October 2015.

17. FDA issues public health warning on phenylpropanolamine.www.fda.gov/drugs/drugsafet y/informationbydrugclass/ucm150763.htm. Accessed on 10 October 2015.

18. Amitava S. Indian market's fixation with fixed dose combinations (editorial). Rational Drug Bulletin. 2002;12:1.

19. Tripathi KD. Drugs and fixed dose combinations banned in India. in: Essentials Of Medical Pharmacology, $5^{\text {th }}$ edition. New Delhi, India. Jaypee Brothers;2004:847-848.

20. Duggin GG. Combination analgesic-induced kidney disease: the Australian experience. Am J Kidney Dis. 1996;28(1):39-47.

Cite this article as: Gor AP, Shah BK. Evaluation of prescribing pattern and adverse effects of fixed dose combination of non-steroidal antiinflammatory drugs. Int J Basic Clin Pharmacol 2016;5:1029-33. 